\title{
Association of Vesicoureteric Reflux (VUR) in Children with Symptomatic Urinary Tract Infection (UTI) - in a Tertiary Care Hospital, Dhaka, Bangladesh
}

\author{
AFROZA BEGUM ${ }^{1}$, HABIBUR RAHMAN ${ }^{2}$, MM HOSSAIN $^{3}$, GOLAM MUINUDDIN $^{4}$ \\ RANJIT RANJAN ROY, ${ }^{5}$ SYED SAIMUL HUQUE ${ }^{6}$
}

\begin{abstract}
:
Background: Vesicoureteric reflux is the most common urinary tract anomaly affecting the children which predisposes to higher rates of urinary tract infection and renal scarring than those without VUR.

Objective: To find out the associations of VUR in children presented with UTI.

Methodology: This cross sectional study was conducted in 36 children aged 1 month to 16 years who were admitted due to UTI in the Pediatric Nephrology Department of Bangabandhu Sheikh Mujib Medical University (BSMMU) from July 2009 to June 2010. UTI were evaluated by urinalysis, culture and sensitivity test, ultrasonography of the urinary system with post-voidal residue and micturating cystourethrogram subsequently.
\end{abstract}

Results: This study revealed that UTI were most frequent in boys $(P<0.001)$. Maximum number $19(52.7 \%)$ of UTI cases were detected between 12 months -60 months age group of children. Highest number of bilateral hydronephrosis $7(71.43 \%)$ and VUR $12(63.15 \%)$ were also detected in the were detected in 2-23 months age group of children. Maximum number of 22/38 kidneys (57.90\%) with refluxing units were detected between 12 months to 60 months (1-5 years) age group and out of this $16(72.72 \%)$ units are of severe grades.

Conclusion: Children presented with UTI along with features of obstructive- uropathy must be investigated early and carefully for VUR to prevent recurrent UTI and renal damage.

Key words: Urinary tract infection, vesico -ureteric reflux, obstructive uropathy.

Introduction:

Vesico-ureteric reflux is the most common urological anomaly of children. ${ }^{1}$ Most often VUR is an incidental finding in children with UTI, when screening is done for urological anomalies. The incidence of VUR has got geographical, racial and gender variation. ${ }^{2-4} \mathrm{~A}$ few studies reported that in asymptomatic UTI the incidence varies from $1 \%-2 \%$ and it is $4.7 \%-51 \%$ in sibs of affected children. ${ }^{5,6}$ But in some recent

1. Associate Professor, Department of paediatric Nephrology, BSMMU

2. Professor, Department of Paediatric nephrology, BSMMU

3. Professor, Department of Paediatric nephrology, BSMMU

4. Professor, Department of Pediatric Nephrology, BSMMU

5. Associate Professor, Department of Paediatric Nephrology, BSMMU

6. Assistant Professor, Department of Paediatric Nephrology, BSMMU

Correspondence: Afroza Begum: begumafrozabegum_ 66@yahoo.com studies from America and Europe showed that the incidence was much higher and it was $17-70 \%$ in children with UTI. ${ }^{2-4,7}$ On the other hand the incidence is much lower $(7 \%)$ in west African descendents. ${ }^{8}$ There are no controversy regarding association of VUR, UTI and renal scarring. It has been established that UTI with unrecognized VUR may lead to increased risk of pyelonephritis and renal scarring leading to its complications like hypertension and impairment of renal function. ${ }^{9-11}$ VUR is the leading cause of chronic kidney disease (CKD) in Turkish and Iranian children respectively. ${ }^{12,13}$ So, early diagnosis and treatment of VUR are of utmost importance to prevent renal scarring and its complications.

Data regarding the incidence of VUR in UTI is not known even either from hospital based or community based study in our country. In this context, we 
evaluated 36 children with UTI to find out the associations of different grades of VUR.

\section{Patients and methods:}

This prospective study was conducted in the Department of Pediatric nephrology, BSMMU, Dhaka over a period of one year from July 2009 to June 2010. Prior to study approval of the ethical review board of BSMMU was taken. All the children from 1 month to 16 years of age with features of UTI were enrolled for the study. In this study, UTI was considered when children were presented with fever, abdominal pain, vomiting, frequency and urgency of micturition and either suprapubic or renal angle tenderness for the first time or in recurrent episodes. Recurrent UTI was defined as at least 2 episodes within 6 months or 3 episodes within one year time. ${ }^{14}$ Urinary tract infection was confirmed when a single pathogenic organism detected by urine culture at a concentration of $1 \times 10^{5}$ / $\mathrm{ml}$ or more in a clean catch mid- stream urine sample or any single pathogen in suprapubic puncture or urobag collection. ${ }^{15}$ Urine culture was done in CLED (cysteine lysine electrolyte deficient agar media). In those cases where antibiotic was already started before sending urine samples for culture sensitivity in symptomatic patients, urine pus cell $>5 / \mathrm{HPF}$ in centrifuged urine was also considered as UTI. ${ }^{15}$

Ultrasonography (USG) of the kidney ureter and bladder (KUB) with post- voidal residue (PVR) was done in all children enrolled in this study. USG was done by 2D machine with curvilinear probe (resolution $3.5 \mathrm{MHz}$ ). All cases with proven UTI undergone micturating cystourethrogram (MCUG) at the end of antimicrobial therapy for a period of 10-14 days or after urine become sterile by urinalysis. The procedure was done by installation of lopamiro through catheter, anterior, full bladder, and micturating snaps were taken. The vesicoureteric reflux was determined by MCUG and was graded according to the international society of VUR. ${ }^{16}$ Grade I reflux was defined as the reflux into the ureter, grade II was reflux into a non-dilated collecting system, grade III was reflux into a mildly dilated collecting system, grade IV was reflux into a moderately dilated collecting system and grade $V$ was reflux into a severely dilated collecting system. For convenience all the kidneys were counted separately and described as renal units.

The Child having recurrent UTI was also evaluated by $X$-Ray lumbosacral spine to exclude spina-bifida or spinal dys-raphism. Other relevant investigations were done for each patient like CBC, ESR, C-reactive protein and renal function status. Data were analyzed by chi-square test (using SPSS software) to measure the level of statistical significance. $P$ value of less than 0.05 was considered as the level of significance.

\section{Result:}

At the beginning of the study 37 children with UTI were enrolled for evaluation. Later on one UTI case was shifted to the Department of Paediatric surgery due to ultimate diagnosis of sacrococcygeal terratoma and was excluded from the study. Finally 36 patients were evaluated. Thirty-six studied cases were divided into three groups according to age; group A (112 months), group B (12-60 months) and group C (>60 months). Group $A$ included 7 patients (mean age $6.71 \pm 3.82$ months), group B 19 patients (mean age $27.53 \pm 14.18$ ) and group $C 10$ patients (mean age $121.20 \pm 21.50$ months). Mean age of the 36 studied cases was $49.50 \pm 48.19$ months (range 2 months to 168 months). In this study the number of male patients were $33(91.7 \%)$ and female were $3(9.3 \%)(p<0.001)$, M: F ratio was 11:1 (table I)

Table-I

Age and sex distribution of the studied children $(n=36)$

\begin{tabular}{lcccc}
\hline Age (months) & \multicolumn{3}{c}{ Geometric } \\
\cline { 2 - 5 } Parameters & ChildrenNo. $(\%)$ & Mean \pm SD & Range & mean \\
\hline -Age (months) & $7(19.4)$ & $6.7 \pm 3.82$ & $2.0-11.0$ & 5.52 \\
Group -A (2-12) & $19(52.8)$ & $27.53 \pm 14.18$ & $12.0-57.0$ & 24.25 \\
Group - B (12-60) & $10(27.8)$ & $121.20 \pm 21.50$ & $96.0-168.0$ & 119.59 \\
Group - C $(>60)$ & 36 & $49.50 \pm 48.19$ & $2.0-168.0$ & 28.33 \\
-Total & $33(91.7)$ & & & \\
Sex & $3(8.3)$ & & \\
Male & $0.0001^{* * *}$ & & \\
Female & & & \\
Pvalue & & & \\
\hline
\end{tabular}

${ }^{* * *}=$ Significant $(P<0.001)-$ Z-test. 
UTI was diagnosed in $22(66.67 \%)$ cases by urine by light microscopy and rest 14(33.33\%) were confirmed by culture and sensitivity test. (Table II) Sonologic evaluation showed that,29(80.55\%) patients had sonological abnormal findings. In which bilateral hydronephrosis was present in $5(71.43 \%), 7(36.84 \%)$ and $3(30 \%)$ children of group A, group B and group $C$ respectively. Unilateral hydronephrosis was present in total $11(30.55 \%)$ patients with the distribution of $2(6.89 \%), 5(17.24 \%)$ and $4(13.79 \%)$ patients in group A, group B and group C. Trabeculation and thickened bladder wall with significant post void residue was present in 7 (19.44\%) and significant post void residue without change in the urinary bladder and upper tract was present in $5(13.89 \%)$ patients. Dilated and elongated posterior urethra was found in $13(36.11 \%)$ patients. One patient had ectopic small sized left kidney and another had horse- shoe kidney. Seven (19.44\%) patients had normal sonographic findings of the urinary tract.(Table-III)

MCUG findings showed that $22(61.11 \%)$ patients had different grades of reflux and highest number of reflux was detected in group B $12(63.15 \%)$, followed by group $C 6(60.00 \%)$ and the least number was in group A 4(57.14\%). (Table IV)
Table-II

Microbiological parameters for diagnosis of UTI in studied cases $(n=36)$

\begin{tabular}{lcc}
\hline Parameters & No. & $\%$ \\
\hline Urine culture & 14 & 38.88 \\
Colony count & & \\
$>105 / \mathrm{ml}$ & & \\
Urine Microscopy & 22 & 61.11 \\
Pus cell & & \\
$>5 / \mathrm{HPF}$ & & \\
\hline
\end{tabular}

To detect reflux, all kidney units were evaluated independently. Out of 72 kidney units 35(48.61\%) were non-refluxing irrespective of age group and mild reflux (grade I-II) was present only in 2/72 kidney units $(2.77 \%$ ), moderate (grade III) in 9/72 kidney units $(12.5 \%)$ and severe (grade IV-V) in 26/72 kidney units (36.11\%) respectively. Severe reflux was present in5/ 14(35.71\%), 16/38(42.10\%) and5/20(25.0\%) in group $A$, group $B$ and group $C$ respectively. Maximum number of refluxing units were detected in group $B$ 22/38 (57.9\%), followed by group A 7/14(50.0\%) and group C 8/20(40.0\%). (Table-V)

Table-III

Sonographic findings of the studied cases $(n=36)$

\begin{tabular}{lccc}
\hline Parameters & Group -A & Group-B & Group-C \\
& $\begin{array}{c}\mathrm{n}=7 \\
(19.44 \%)\end{array}$ & $\mathrm{n}=19$ & $\mathrm{n}=10$ \\
& $0(0.00)$ & $5(26.31)$ & $(27.78 \%)$ \\
\hline Normal $\mathrm{n}=7(19.44 \%)$ & & & $2(20.00)$ \\
Abnormal $\mathrm{n}=29(80.55 \%)$ & $5(71.43)$ & $7(36.84)$ & $3(30.00)$ \\
Hydronephrosis Bilateral & $2(28.57)$ & $5(26.31)$ & $4(40.00)$ \\
Hydronephrosis Unilateral & $2(28.57)$ & $3(15.89)$ & $2(20.00)$ \\
Thickend \& trabeculated bladder wall & $1(14.28)$ & $3(15.79)$ & $1(10.00)$ \\
Significant PVR without change in urinary & & & \\
bladder and upper tract & $4(57.14)$ & $6(31.58)$ & $3(30.00)$ \\
Dilated and elongated posterior urethra & $0(0.00)$ & $0(0.00)$ & $1(10.00)$ \\
Ectopic Kidney & $0(0.00)$ & $1(5.21)$ & $0(0.00)$ \\
Horse-shoe Kideny & & &
\end{tabular}


Table-IV

MCUG findings of the studied subjects $n=36$

\begin{tabular}{lcc}
\hline Reflux & $\begin{array}{c}\text { Present } \\
22(61.11 \%)\end{array}$ & $\begin{array}{c}\text { Absent } \\
14(38.89 \%)\end{array}$ \\
\hline Group - A $n=7$ & $4(57.14)$ & $3(42.85)$ \\
Group - B $n=19$ & $12(63.15)$ & $7(36.84)$ \\
Group - C $n=10$ & $6(60.00)$ & $4(40.00)$ \\
\hline
\end{tabular}

Table-V

MCUG findings of the renal units $(n=72)$ in different age groups of the study cases.

\begin{tabular}{lccc}
\hline VUR grades & \multicolumn{3}{c}{ Age (Months) } \\
\cline { 2 - 4 } & $\begin{array}{c}\text { Group A } \\
(n=14)\end{array}$ & $\begin{array}{c}\text { Group B } \\
(n=38)\end{array}$ & $\begin{array}{c}\text { Group C } \\
(n=20)\end{array}$ \\
& No. $(\%)$ & No. $(\%)$ & No. (\%) \\
\hline 0 & $9(64.28)$ & $16(42.1)$ & $10(50)$ \\
I & $00(0.0)$ & $01(2.63)$ & $00(0.0)$ \\
II & $00(0.0)$ & $01(2.63)$ & $00(0.0)$ \\
III & $02(14.28)$ & $04(10.52)$ & $03(15.0)$ \\
IV & $03(21.42)$ & $10(26.3)$ & $03(15.0)$ \\
V & $02(14.28)$ & $06(15.78)$ & $02(10.0)$ \\
\hline
\end{tabular}

\section{Discussion:}

The prevalence of VUR in children with UTI varies among the racial groups and also differs in genders. It is more common in white people and in girls. Chand et al found that females are twice as males to have VUR and white children are three times as likely to have VUR than blacks. ${ }^{2}$ This study analyzed 36 children with UTI to determine the prevalence of VUR. Though we know the incidence of UTI is many fold higher in females than males after infancy, but in this study $91.7 \%$ children were male and only $8.3 \%$ children were female. (table-I) The difference of sex wise distribution was significant $(P<0.001)$. This difference is probably due to risk factors of recurrent UTI like obstructive uropathy which was mostly found in male child. ${ }^{17}$ and also due to more attention by the guardians regarding illness of male child in our country. This observation about complicated UTI with obstructive uropathy was also supported by Gorelick $\mathrm{MH} .{ }^{10}$ Male predominance of UTI was also found in other Asian studies. ${ }^{11-13}$ The mean age of patients at presentation was fairly high in our study population, which is probably due to unawareness or underevaluation of the previous UTIs.
Different studies from USA, UK, France and Australia showed that $25 \%-60 \%$ of children with UTI had associated VUR. ${ }^{18-20,21,22, ~ T h e ~ l o w e s t ~ p r e v a l e n c e ~ i s ~}$ in black Americans 6\%-12\%. . $^{2-4}$ Venhola et al conducted a large study on children with UTI in Finland recently and had shown that $36 \%$ of children with proven UTI , $28 \%$ with possible UTI and $36 \%$ with improbable UTI had associated VUR. ${ }^{23}$ Howard et al. reported the presence of VUR in $39 \%$ of symptomatic Chinese children with UTI. ${ }^{24}$ The prevalence is lesser in Iranian and Nepalese children(30\% and35\% respectively) ${ }^{12,13}$

In our study, we evaluated 36 children with UTI of both sexes by USG of the KUB region with post-voidal residue and by MCU to detect VUR. Sonological evaluation gives important initial clue to the anatomical or structural abnormalities of the urinary tract associated with UTI. ${ }^{25}$ Twenty-nine $(80.55 \%)$ patients had different types of sonological abnormalities. There are controversies about the role of ultrasonography for evaluation of UTI. It was the preferred investigation for evaluation of UTI previously. ${ }^{10}$ Some authors found important indications of doing USG in evaluation of UTI. ${ }^{26,27}$ But others showed that it is not sensitive nor specific for detection of VUR in children with first UTI. ${ }^{28,29}$ Even though it is done routinely in some centers for evaluation of lower urinary tract in children with first UTI to exclude congenital anomalies particularly when the prenatal USG evaluation was absent. Current American Academy of Pediatrics Practice guideline recommend routine imaging (USG and either VCUG or radionuclide cystography) after the initial UTI in febrile infants and young children. ${ }^{30}$ In our country where antenatal check -up is insufficient, all the expectant mothers are not fortunate enough to have antenatal sonologic evaluation. So, we have done the USG of KUB with PVR in all the children with first febrile UTI.

In this study, 22out of 36(61.11\%) patients had different grades of reflux.(table IV) This figure is similar to the study done by Bhatnagar et $\mathrm{al}^{11}$ in India where they found $62 \%$ children with UTI had VUR ( majority in grade $\mathrm{V}$ ) but higher than the studies done by the other workers of different countries. ${ }^{17,18,20,24}$ Zaki et al. found the incidence of reflux $22 \% .{ }^{31}$ This difference may be due to that our country and India have more or less similar geographical, cultural and socioeconomic background and both the studies were done in tertiary level hospital and the patients reach there late due to parental ignorance, poverty and late 
referral by the primary and secondary care givers. In this study higher frequency of VUR has been found in older children (Table IV). It is well known that reflux associated UTI is more common in younger age group. In a study from USA Chand et al found that age wise incidence of VUR was $52 \%$ in $0-2$ years, $26 \%$ in 3-6 years, $18 \%$ in $7-11$ years and $4 \%$ in $12-21$ years of age. ${ }^{2}$ Similar result was found by Zaki et al. ${ }^{31}$ In our study, the incidence and severity of grades of VUR in children is higher than the studies done by Chand et al and Zaki et al. $.2,31$ The lack of antenatal sonologic evaluation and late referral of the patients are the two important risk factors that differs the present study with others.

Among 36 patients with 72 renal units, reflux was present in 35 units $(48.6 \%)$. Of the refluxing units mild (grade I, II), moderate (grade III) and severe (grade IV and $V$ ) reflux was found in 4(11.42\%), 11(31.42\%) and $20(57.14 \%)$ renal units respectively. The prevalence of reflux is similar to the results of a coordinated research project done by Orellana P et al where VUR was detected in $43.49 \%$ of the renal units with first and recurrent UTI but higher than the study done by Soylu A (36.8\%). ${ }^{32,33}$ In our study grade III-V reflux was present in 31 renal units which comprises $88.56 \%$ of the refluxing units. This figure is much higher than the study by Orellana $\mathrm{P}$ et al where moderate to severe grades were present in $43.16 \%$ kidneys. ${ }^{32}$ The higher incidence of reflux with advanced grades in our study again reflects parental ignorance and late referral of the patients who ultimately reach at our center with advanced stage of the disease.

The aim of our study was to determine the association of VUR in children presented with UTI in a tertiary hospital, it may not reflected the actual prevalence because patients with complicated UTI were referred here from different primary and secondary centers which may overestimated the result.

\section{Conclusion:}

Vesico-ureteric reflux is a common association in children with urinary tract infection even in first episode. So, imaging studies like USG and MCUG is mandatory for detection of VUR grading to decide treatment modality and also to prevent ultimate detrimental effects of UTI and VUR on renal cortical tissue.

\section{Acknowledgement:}

We acknowledge the University Grants Commission (UGC) of Bangladesh for funding this project.

\section{References:}

1. Skoog SJ,Peters CA, Arant BS Jr, Copp HL, Elders JS, Hudson RG et al.Pediatric Vesicoureteral Reflux Guidelines Panel Summery Report : Clinical Practice Guidelines for Screening Siblings of Children with VUR neonates/ infants with prenatal Hydronephrosis. J Urol 2010; 184(3): 1145-55.

2. Chand DH, Rhoades T, Poe SA, Kraus S, Strife $\mathrm{CF}$. Incidence and severity of vesicoureteral reflux in children related to age, gender, race and diagnosis. J Urol 2003;170(4 pt2): 1548-50.

3. Melhem RE, Harpen MD. Ethnic factors in the variability of primary vesicoureteral reflux with age. Peditr Radiol 1997;27:750-51.

4. Askari A, Belmen AB. Vesicoureteral reflux in black girls. J Urol 1982: 127: 747-48.

5. American Academy of pediatrics .The diagnosis, treatment, and evaluation of the initial urinary tract infection in febrile infants and young children. Peditrics 1999; 103: 843-85.

6. Menezes M, Puri P. Familial vesicoureteral reflux - is screening beneficial? J Urol 2009; 182(4 suppl): 1673-77.

7. Ataei N, Madani A, Esfahani ST, Kezbafzadeh A, Ghaderi O, Jalili S, Sharafi B. Screening for vesicoureteral reflux and renal scars in siblings of children with known reflux. Pediatr Nephrol 2004;19:1127-1131.

8. Noe HN. The long term results of prospective sibling reflux screening.J Urol 1992; 148: 1739-1742.

9. R. Oostenbrink, AJ vander Heijden, KGM Moons, HA Mall . Prediction of vesicoureteral reflux in childhood urinary tract infection: A multivariate approach. Acta Paediatr 2000; 89: 806-10.

10. Gorelick MH, Shaw KM. Screening test for urinry tract infection in children. Pediatr nephrol 1996; 10: 395-401.

11. Bhatnagar V, Mitra DK, Agarwala S, Kumar R, Patel C, Malhotra AK et al. The role of DMSA scan in evaluation of the correlation between urinary tract infection, vesicoureteral reflux and renal scarring.Pediatr. Surg Int 2002;18(2-3): 128-34.

12. Sharbaf TG, Fallahzadeh MH, Modarresi AR, Esmaeli M. Primary vesicoureteral reflux in 
Iranian children. Indian Pediatr 2007; 44: 128-130.

13. Shrestha S, Basukala S, Pokhrel N. Primary vesicoureteral reflux in Nepalese children. Kathmundu Univ Med J 2008; 6: 75-8.

14. William G,Craig JC. Long term antibiotics for preventing recurrent urinary tract infection in children. Cochrane Database system Review.2011; (3): CD001534.

15. Graham IC, Galloway A. ACP Best Practice No 167:The laboratory diagnosis of urinary tract infection. J Clin pathol 2001;54:911-9.

16. Lebowitz RL, Olbing H, Parkkulainen KV, Smellie JM, Tamminen-Mobius TE. International System of Radiographic Grading of Vesico-Ureteric Reflux Study in children. Pediatr Radiol 1985; 15: 105-09.

17. William SG, Jeffery T, Fletcher JT, Alexander SI, Craig JC. VUR. J Am Soc Nephrol; 19(5):847862 Hannula A, Venhola M, Perhomaa m, Pokka T, Renko M, Uhari M . Vesicoureteral reflux in children with suspected and proven Urinary tract infection. Pediatr nephrol 2010; 25: 1463-9.

18. Hannula A, Venhola M, Perhomaa m, Pokka T, Renko M, Uhari M. Vesicoureteral reflux in children with suspected and proven Urinary tract infection. Pediatr nephrol 2010; 25: 1463-9.

19. William SG, Jeffery T, Fletcher JT, Alexander SI, Craig JC. Vesicoureteral reflux. J Am Soc Nephrol 2008; 19:847-62.

20. Swerkersson S, Jodal U, Sixt R, Stockland E, Hansson S. Relationship among Vesicoureteral reflux, Urinary tract infection and renal damage in children. Journal of urol 2007; 78: 647-51.

21. Snodgrass $W$. Relationship of voiding dysfunction to urinary tract infection and vesicoureteric reflux in children. Urology 1991; 38: $341-4$

22. Leory S, Marc E, Adamsbaom C, Gendrel D, Beart G, Chalu Meau M. Prediction of Vesicoureteral reflux after a first febrile urinary tract infection in children: validation of a clinical decision rule. Archive Dis Child 2006; 91: 241-44.

23. Venhola M, Hannula A, Huttunen NP, Renko M, Pokka J, Uhari M. Occurrence of Vesicoureteral reflux in children. Acta Pediatr 2010; 99: 1875-78.
24. RG Howard, Fran CCR, DJ Roebuck,FRCR, FRANZCR, P Au Yeung et al. Vesicoureteral reflux and renal scarring in Chinese children. British journal of radiology 2004;74: 331-34.

25. Huang HP, Lae YC, Tsai IJ, Chen SY, Tsau YK. Renal ultrasonography should be done routinely in children with urinary tract infection. Urology 2008; 71: 439-43.

26. Brader P, Riccabona M, Schwartz T, Seebachur $U$, Ring E. Value of comprehensive renal ultrasound in children with acute urinary tract infection for assessment of renal involvement: comparison with DMSA scintigraphy and final diagnosis. Eur Radiol 2008; 18: 2981-9.

27. Preda I, Jodal U, Sixt R, Stokland E, Hansson $S$. Value of ultrasound in evaluation of infants with first urinary tract infection. J Urol 2010; 183: 1984-88.

28. Sandrine L, Sebastien V, Anis L, Hubert D, Albert $B$. Vesicoureteral reflux in children with urinary tract infection: Comparison of diagnostic accuracy in renal ultrasonographic criteria. Radiol 2010; 255: 890-98.

29. Mahant S, Friedman J, Mac Arthur C. Renal ultrasonogram findings and vesicoureteral reflux in children hospitalized with VUR. Arch Dis child 2002; 86: 419-20.

30. American academy of Pediatrics. Practice parameter; the diagnosis, treatment and evaluation of initial urinray tract infection in febrile infants and young children. Pediatrics 1999; 103:843-52.

31. Zaki M, Mutari GA, Badawi M, Ramadan D, Hanafi EAD. Vesicoureteric reflux in Kuwaiti children with first febrile urinary tract infection, Pediatr Nephrol 2003; 18: 898-901.

32. Orellana $\mathrm{P}$, Baquedano $\mathrm{P}$, Rangarajan $\mathrm{V}$, Zhao $\mathrm{JH}$, Eng NDC, Fettich J, Chaiwatanarat T, Sonmezoglu K, Kumar D, Park YH, Samuel AM, Sixt R, Bhatnagar V, Padhy AK. Relationship between acute pyelonephritis, renal scarring, and vesicoureteral reflux. Results of a coordinated research project. Pediatr Nephrol 2004; 19: 1122-26.

33. Soylu A, Demir BK, Turkmen M, Bekem O, Saygi $\mathrm{M}$, cakmakei H, Kavukeu S. Predictors of renal scars in children with urinary tract infection and vesico-ureteral reflux. Pediatr Nephrol 2008; 23: 2227-32 